\title{
DC fault analysis for modular multilevel converter-based system
}

\author{
Bin $\mathrm{LI}^{1}$, Jiawei $\mathrm{HE}^{1}$, Jie TIAN ${ }^{2}$, Yadong $\mathrm{FENG}^{2}$, Yunlong DONG ${ }^{2}$
}

\begin{abstract}
DC fault protection is the key technique for the development of the DC distribution and transmission system. This paper analyzes the transient characteristics of DC faults in a modular multilevel converter (MMC) based DC system combining with the numerical method. Meanwhile, lots of simulation tests based on MATLAB/Simulink are carried out to verify the correctness of the theoretical analysis. Finally, the technological difficulties of and requirements for the protection and isolation are discussed to provide the theoretical foundation for the design of dc fault protection strategy.
\end{abstract}

Keywords DC system, DC fault analysis, DC fault protection, Modular multilevel converter

CrossCheck date: 18 October 2015

Received: 5 June 2015/Accepted: 19 October 2015/Published online: 12 January 2016

(C) The Author(s) 2016. This article is published with open access at Springerlink.com

$\triangle$ Jiawei HE

hejiawei_tju@126.com

Bin LI

binli@tju.edu.cn

Jie TIAN

tianj@nrec.com

Yadong FENG

fengyd@nrec.com

Yunlong DONG

dongly@nrec.com

1 Key Laboratory of Smart Grid of Ministry of Education, Tianjin University, Tianjin, China

2 NR Electric, Nanjing, China

\section{Introduction}

With the extensive development of distributed generations like the wind power and photovoltaic power [1], as well as the ever increase of electric vehicles [2] and other DC loads, the DC system is drawing growing research interests due to advantages of low power loss, low investment, high reliability and so on [3, 4]. Supported by the evolution of the power-electronic technology [5], the flexible DC system is gaining popularity due to the advantages such as having an independent power control and being immune to commutation failure [6].

In engineering practice, the two-level voltage source converter (VSC) has been acknowledged as a viable device to integrate the distributed generations and DC loads. However, it has drawbacks such as high switching frequency, great switching power loss and poor power quality [7]. In this context, the idea of the MMC technique proposed in $[8,9]$ based on the modular design has a low switching frequency and better power quality [10].

Presently, several technical challenges to the development of DC system are confronting us, among which is the DC fault protection, including the fault detection and fault isolation.

The conventional converters, including the VSC and MMC, are not able to isolate the DC fault by themselves. Even the sub-modules in the converter are all blocked, the freewheeling diodes still act as an uncontrolled rectifier. Nowadays, there are typically three DC fault isolating methods.

1) The most ideal isolating method is interrupting the fault circuit by DC circuit breakers [11], which, however, are still not available for engineering application. Because there is no DC circuit breaker that could meet the requirements of interrupting capacity and action speed. 
2) Due to the technical difficulty of the DC circuit breaker, an AC-circuit-breaker-based isolating method which could interrupt the DC fault circuit reliably was proposed in [12]. However, drawbacks of this method are obvious: slow response of the mechanical AC switch gear and large blackout area of the system.

3) Because of the reasons above, researchers are looking into the third method, i.e., eliminating the DC fault current by the converter. Reference [13] proposed a new MMC sub-module topology with DC fault current eliminating capability. After a DC fault happens, the fault current could be eliminated due to the reverse voltage from the capacitors in sub-modules. Reference [14] proposed the doublethyristor switch scheme which prevents the AC-side current contribution and allows the DC cable current freely decay to zero. However, the drawbacks like the thyristors withstanding high $\mathrm{d} v / \mathrm{d} t$ in the normal operation should be taken into account. Reference [15] designed an isolating method which could reduce the level of $\mathrm{d} v / \mathrm{d} t$ that thyristors have to withstand.

There has been a lot of work focusing on the fault isolation, however, the work on fault detection with identification capability is still rarely done. Therefore, it is necessary for us to make sense of DC fault transient characteristics. Reference [16] has done a detailed analysis for the DC faults in the two-level VSC based DC system. Because the topology of a MMC is different from the two-level VSC, it is important to investigate the transient characteristics of DC faults in a MMC-based DC system.

The works of this paper are as follows: Firstly, this paper analyzes the transient characteristics of a DC fault in the MMC-based DC system, which are different from the characteristics in a VSC-based one [16], providing the theoretical foundation for the design of the DC fault protection. Secondly, based on the fault characteristics, this paper discusses the technological difficulties of and requirements for the protection against DC faults in the DC system. In addition, the correctness of the theoretical analysis is verified by the simulation tests in MATLAB/ Simulink.

\section{Fault analysis for MMC-based DC system}

Figure 1 shows a symmetrical bipolar DC system connected with the AC system by MMC. A MMC consists of three parallel-connected phase-units. One phase-unit comprises two arms, each with identical sub-modules (SMs) series-connected, as shown in Fig. 1. Owing to advantages like low switching losses, minor total harmonic distortion and modular design, etc, MMCs prove superior for constructing efficient DC distribution and transmission system.

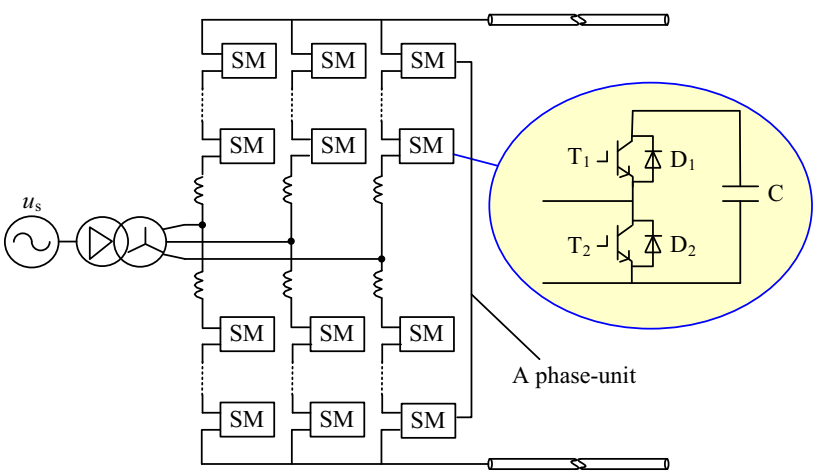

Fig. 1 Structure of MMC-based DC system

Each SM is mainly comprised of two IGBTs $\left(T_{1}, T_{2}\right)$, two freewheeling diodes $\left(\mathrm{D}_{1}, \mathrm{D}_{2}\right)$, as well as a cell capacitor (C). Compared with the conventional two-level VSC, the only difference during the normal operation is the modulation strategy. MMC adopts the step pulse modulation which has advantages such as low switching losses and high waveform quality in contrast with the pulse-width modulating (PWM) that the two-level VSC adopts [9].

Fault current isolating technique and protection strategy are vital to the stability and reliability of the power grid. For this reason, it is essential to investigate DC fault transient characteristics and its influence on the DC-side system, AC-side system and converter. There are three kinds of DC faults, i.e., DC disconnection fault, DC poleto-ground fault and DC pole-to-pole fault. Generally, the damage of a DC pole-to-pole fault is the severest [17]. So this paper analyzes the transient characteristics of a DC fault under the DC pole-to-pole fault condition.

In the field application, all the IGBTs would be soon turned off after a DC short-circuit fault. Fig. 2 illustrates the fault current path before and after turning off the IGBTs. Consequently, the DC fault transient process could be divided into three stages, namely 'SMs normal operation stage', 'Initial stage after blocking SMs' and 'Uncontrolled rectifier stage'.

\subsection{SMs normal operation stage}

In this stage, the MMC is still working with the normal control strategy. The DC fault current is supplied by the AC-side source and cell capacitors in the on-state SMs. Therefore, the fault current flowing path could be illustrated as the red line in Fig. 2a, where we simply look into phase-A under a DC pole-to-pole fault condition, and the analysis can also be applied to phases $\mathrm{B}$ and $\mathrm{C}$.

In Fig. 2a, $u_{\mathrm{sa}}$ is the phase-A AC voltage; $R_{\mathrm{S}}$ and $L_{\mathrm{s}}$ are the equivalent impedance sum of the AC-side system and the transformer; $R$ and $L$ are the resistance and inductance of the arm reactors; $R_{1}$ and $L_{1}$ are the equivalent resistance 


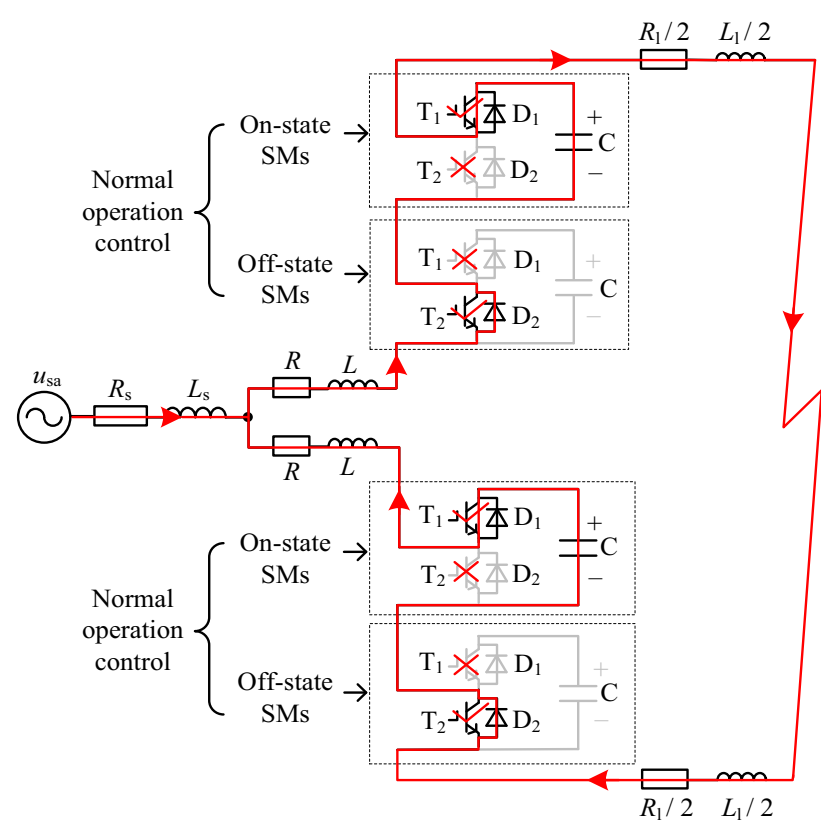

(a) Before SMs being blocked

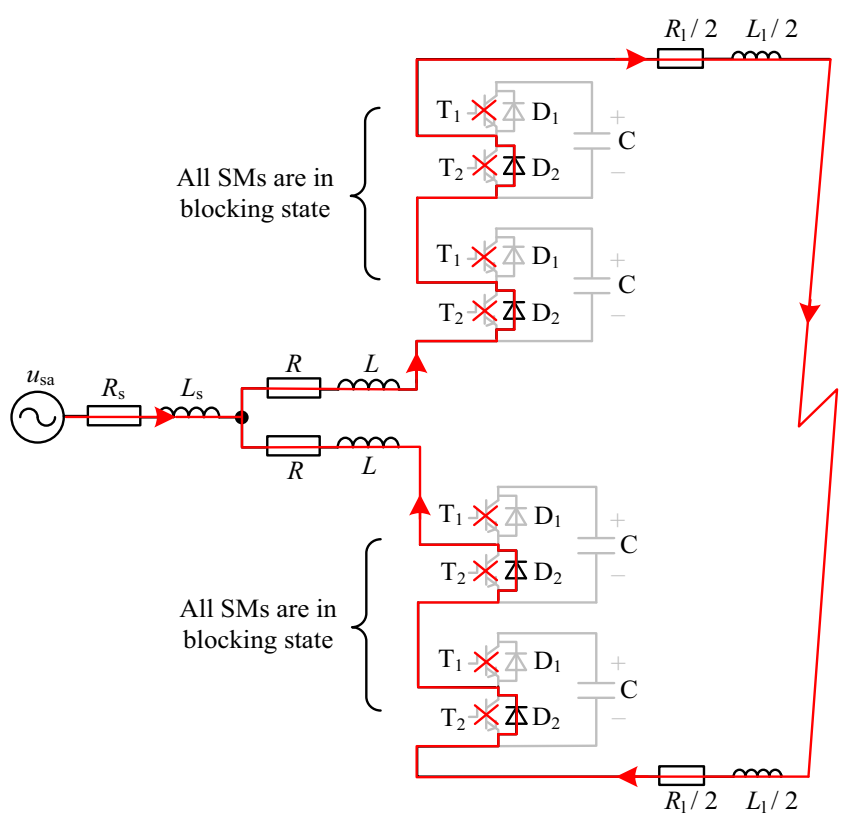

(b) After SMs being blocked

Fig. 2 Equivalent circuit of DC pole-to-pole fault

and inductance of DC short-circuit cable. Generally, the DC system is earthed through large parallel resistors. Since the resistance of the fault circuit is very small, the parallel resistors can be ignored. Similarly, the distributed capacitor of the DC cable is also negligible compared with cell capacitors.

The short circuit can be simplified as the one in Fig. 3. It can be known that the numbers of on-state SMs in each arm are not equal when a DC fault happens, according to the normal operation control strategy. For the AC-side system, the DC fault should be considered as an unsymmetrical fault. And the solving of its transient process involves high order multidimensional differential equations, which makes it hard to obtain an analytic solution. So we opt for the numerical calculation method.

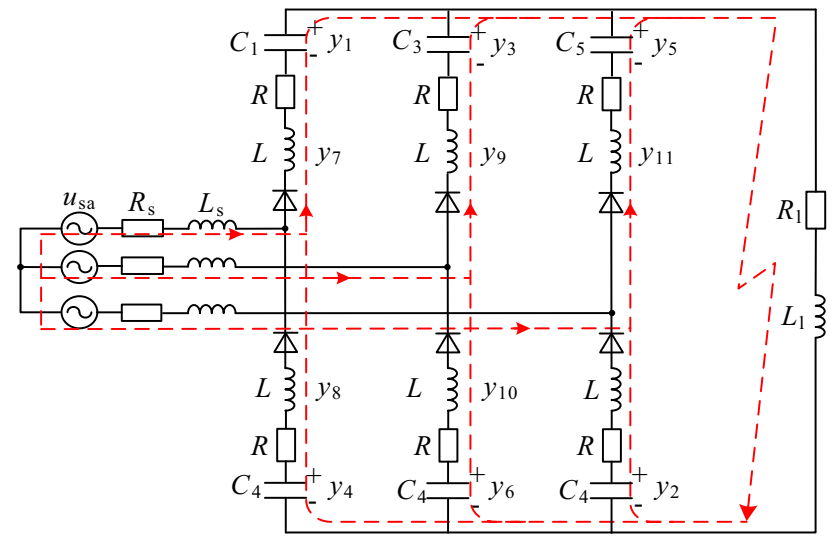

Fig. 3 Equivalent fault circuit during SMs normal operation stage
In Fig. 3, there are 16 energy storage components and 5 cut-sets only consisting of inductances, so we get 11 state variables. And we select 6 capacitor voltages $\left(y_{1} \sim y_{6}\right)$ and 5 arm reactor currents $\left(y_{7} \sim y_{11}\right)$ as the state variables. The forward directions of the state variables are also noted. Then the transient state can be expressed as

$$
\left\{\begin{array}{l}
y_{1}-R y_{7}-L y_{7}^{\prime}-L y_{8}^{\prime}-R y_{8}+y_{2} \\
\quad=y_{3}-R y_{9}-L y_{9}^{\prime}-L y_{10}^{\prime}+y_{4} \\
y_{1}-R y_{7}-L y_{7}^{\prime}-L y_{8}^{\prime}-R y_{8}+y_{2}=y_{5}-R y_{11} \\
\quad-L y_{11}^{\prime}-L\left(y_{7}^{\prime}+y_{9}^{\prime}+y_{11}^{\prime}-y_{8}^{\prime}-y_{10}^{\prime}\right) \\
-R\left(y_{7}+y_{9}+y_{11}-y_{8}-y_{10}\right)+y_{6} \\
y_{1}-R y_{7}-L y_{7}^{\prime}-L y_{8}^{\prime}-R y_{8}+y_{2}= \\
R_{1}\left(y_{7}+y_{9}+y_{11}\right)+L_{1}\left(y_{7}^{\prime}+y_{9}^{\prime}+y_{11}^{\prime}\right) \\
u_{\mathrm{sa}}-R_{\mathrm{s}}\left(y_{7}-y_{8}\right)-L_{\mathrm{s}}\left(y_{7}-y_{8}\right)-L y_{7}^{\prime}-R y_{7}+y_{1} \\
=u_{\mathrm{sb}}-R_{\mathrm{s}}\left(y_{9}-y_{10}\right)-L_{\mathrm{s}}\left(y_{9}^{\prime}-y_{10}^{\prime}\right)-L y_{9}^{\prime}-R y_{9}+y_{3} \\
u_{\mathrm{sa}}-R_{\mathrm{s}}\left(y_{7}-y_{8}\right)-L_{\mathrm{s}}\left(y_{7}-y_{8}\right)-L y_{7}^{\prime}-R y_{7}+y_{1}=u_{\mathrm{sc}} \\
-R_{\mathrm{s}}\left(y_{8}+y_{10}-y_{7}-y_{9}\right)-L_{\mathrm{s}}\left(y_{8}^{\prime}+y_{10}^{\prime}-y_{7}^{\prime}-y_{9}^{\prime}\right) \\
\quad-L y_{11}^{\prime}-R y_{11}+y_{5} \\
C_{1} y_{1}^{\prime}=-y_{7}, C_{2} y_{2}^{\prime}=-y_{8}, C_{3} y_{3}^{\prime}=-y_{9}, C_{4} y_{4}^{\prime}=-y_{10} \\
C_{5} y_{5}^{\prime}=-y_{11}, C_{6} y_{6}^{\prime}=-\left(y_{7}+y_{9}+y_{11}-y_{8}-y_{10}\right)
\end{array}\right.
$$

Equation (1) could be expressed by a matrix form showed as

$$
\left[\begin{array}{l}
y_{1}^{\prime} \\
\vdots \\
y_{11}^{\prime}
\end{array}\right]=-A^{-1} B\left[\begin{array}{l}
y_{1} \\
\vdots \\
y_{11}
\end{array}\right]-A^{-1} C\left[\begin{array}{l}
u_{\mathrm{sa}} \\
u_{\mathrm{sb}} \\
u_{\mathrm{sc}}
\end{array}\right]
$$




$A=\left[\begin{array}{ccccccccccc}0 & 0 & 0 & 0 & 0 & 0 & -L & -L & L & L & 0 \\ 0 & 0 & 0 & 0 & 0 & 0 & 0 & -2 L & L & -L & 2 L \\ 0 & 0 & 0 & 0 & 0 & 0 & -\left(L+L_{1}\right) & -L & L_{\mathrm{l}} & 0 & -L_{\mathrm{l}} \\ 0 & 0 & 0 & 0 & 0 & 0 & -\left(L_{\mathrm{s}}+L\right) & L_{\mathrm{s}} & L_{\mathrm{s}}+L & -L_{\mathrm{s}} & 0 \\ 0 & 0 & 0 & 0 & 0 & 0 & -\left(2 L_{\mathrm{s}}+L\right) & 2 L_{\mathrm{s}} & -L_{\mathrm{s}} & L_{\mathrm{s}} & L \\ C_{1} & 0 & 0 & 0 & 0 & 0 & 0 & 0 & 0 & 0 & 0 \\ 0 & C_{2} & 0 & 0 & 0 & 0 & 0 & 0 & 0 & 0 & 0 \\ 0 & 0 & C_{3} & 0 & 0 & 0 & 0 & 0 & 0 & 0 & 0 \\ 0 & 0 & 0 & C_{4} & 0 & 0 & 0 & 0 & 0 & 0 & 0 \\ 0 & 0 & 0 & 0 & C_{5} & 0 & 0 & 0 & 0 & 0 & 0 \\ 0 & 0 & 0 & 0 & 0 & C_{6} & 0 & 0 & 0 & 0 & 0\end{array}\right] ;$

$B=\left[\begin{array}{ccccccccccc}1 & 1 & -1 & -1 & 0 & 0 & -R & -R & R & R & 0 \\ 1 & 1 & 0 & 0 & -1 & -1 & 0 & -2 R & R & -R & 2 R \\ 1 & 1 & 0 & 0 & 0 & 0 & -\left(R+R_{\mathrm{l}}\right) & -R & -R_{\mathrm{l}} & 0 & -R_{\mathrm{l}} \\ 1 & 0 & -1 & 0 & 0 & 0 & -\left(R_{\mathrm{S}}+R\right) & R & R+R_{\mathrm{s}} & -R_{\mathrm{S}} & 0 \\ 1 & 0 & 0 & 0 & -1 & 0 & -\left(2 R_{\mathrm{s}}+L\right) & 2 R_{\mathrm{s}} & -R_{\mathrm{S}} & R_{\mathrm{S}} & R \\ 0 & 0 & 0 & 0 & 0 & 0 & 1 & 0 & 0 & 0 & 0 \\ 0 & 0 & 0 & 0 & 0 & 0 & 0 & 1 & 0 & 0 & 0 \\ 0 & 0 & 0 & 0 & 0 & 0 & 0 & 0 & 1 & 0 & 0 \\ 0 & 0 & 0 & 0 & 0 & 0 & 0 & 0 & 0 & 1 & 0 \\ 0 & 0 & 0 & 0 & 0 & 0 & 0 & 0 & 0 & 0 & 1 \\ 0 & 0 & 0 & 0 & 0 & 0 & 1 & -1 & 1 & -1 & 1\end{array}\right] ;$

$C=\left[\begin{array}{ccccccccccc}0 & 0 & 0 & 1 & 1 & 0 & 0 & 0 & 0 & 0 & 0 \\ 0 & 0 & 0 & -1 & 0 & 0 & 0 & 0 & 0 & 0 & 0 \\ 0 & 0 & 0 & 0 & -1 & 0 & 0 & 0 & 0 & 0 & 0\end{array}\right]^{\mathrm{T}}$

Then we can get the state equation format showed as

$$
\left\{\begin{array}{r}
y_{1}^{\prime}=f_{1}\left(t, y_{1}, y_{2}, \cdots, y_{11}\right) \\
y_{2}^{\prime}=f_{2}\left(t, y_{1}, y_{2}, \cdots, y_{11}\right) \\
\vdots \\
y_{11}^{\prime}=f_{11}\left(t, y_{1}, y_{2}, \cdots, y_{11}\right)
\end{array}\right.
$$

The equations can be solved with the following RungeKutta formula

$$
\left\{\begin{array}{l}
y_{i, n+1}=y_{i, n}+\frac{h}{6}\left(k_{i 1}+2 k_{i 2}+2 k_{i 3}+k_{i 4}\right) \\
k_{i 1}=f_{i}\left(t_{n}, y_{1 n}, y_{2 n}, \cdots, y_{11 n}\right) \\
k_{i 2}=f_{i}\left(t_{n}+\frac{h}{2}, y_{1 n}+\frac{h}{2} k_{11}, y_{2 n}+\frac{h}{2} k_{21}, \cdots, y_{11 n}+\frac{h}{2} k_{m 1}\right) \\
k_{i 3}=f_{i}\left(t_{n}+\frac{h}{2}, y_{1 n}+\frac{h}{2} k_{12}, y_{2 n}+\frac{h}{2} k_{22}, \cdots, y_{11 n}+\frac{h}{2} k_{m 2}\right) \\
k_{i 4}=f_{i}\left(t_{n}+h, y_{1 n}+h k_{13}, y_{2 n}+h k_{23}, \cdots, y_{11 n}+h k_{m 3}\right) \\
i=1,2, \cdots, m \quad m=11
\end{array}\right.
$$

where $t_{n}$ is the sampling sequence number; $y_{i, n}$ and $y_{i, n+1}$ are the values of variable $y_{i}$ at the moments of $t_{n}$ and $t_{n+1}$; $h$ is the iterative calculation step.

By solving (3), we get the transient response of state variables. Figure 4 shows the simulation and calculation results, where $i_{\mathrm{dc}}$ is the current flowing through the DC cable; $i_{\text {a_up }}$ is the upper arm current of phase A. (Here we set the fault happens at $10 \mathrm{~km}$ far from the exit of the MMC at $t=0 \mathrm{~s}$, and the detailed parameters of the simulated system are shown as Appendix A.)

From Fig. 4, the theoretical analysis result of the fault current in this paper is very close to the simulation result.
And the result also shows that not only the fault current goes up rapidly, but also the current variation rate $\mathrm{d} i / \mathrm{d} t$ keeps in a high level. As we know, the electric equipments may be unable to bear large short-circuit current, and a high di/ $\mathrm{d} t$ would lead to the burning of IGBTs because of the local overheating. Therefore, in field application, if the fault detection is not fast enough to block the SMs, they would also be blocked at once the fault current or $\mathrm{d} i / \mathrm{d} t$ exceeds the threshold values of the self-protection for IGBTs. After that, the transient process would come into the next stage named as 'Initial stage after blocking SMs blocked.

\subsection{Initial stage after blocking SMs}

In the circuit shown as Fig. 2b, freewheeling diodes $D_{2}$ will still bear a large fault current even if all IGBTs have been turned off. In this stage, the cell capacitors in the SMs are bypassed by the fault current, and thus would cease discharging. In other words, the cell capacitors discharge through and only in the first stage discussed in Section 2.1.

However, the reactors in the arms enable all freewheeling diodes marked as $\mathrm{D}_{2}$ to conduct continuously even after the capacitor discharge stops. Meanwhile, the AC-side source feeds the fault current through diodes and arm reactors. And the diodes enable the flow of the AC current all the time in spite of the unidirectional characteristic because of the freewheeling current from the reactors. In this case, the fault circuit is equivalent to that in Fig. 5.

According to the superposition theorem, the fault current is contributed by the current fed by the AC-side source and that provided by the arm reactor. Since the latter will keep all the diodes $\mathrm{D}_{2}$ working under this circumstance, the DC fault can be analyzed as a three-phase short circuit fault for the AC-side system, and the circuit is equivalent to that in Fig. 6a. Meanwhile, the discharge of the arm reactors is illustrated in Fig. 6b.

At the moment SMs are blocked, we assume the voltage and the current of phase A are $u_{\mathrm{sa}}=U_{m} \sin \left(\omega t+\varphi_{0}\right)$ and $I_{\mathrm{sa} 0}$ respectively, and the current of the DC cable is $I_{\mathrm{dc} 0}$. According to the solving method of the dynamic circuit, the phase-A current $i_{\mathrm{sa}}$ and the DC cable current $i_{\mathrm{dc}}$ are solved as

$i_{\mathrm{sa}}=I_{m} \sin \left(\omega t+\varphi_{0}-\varphi\right)+\left[I_{\mathrm{a} 0}-I_{m} \sin \left(\varphi_{0}-\varphi\right)\right] \mathrm{e}^{-\frac{\mathrm{t}}{\tau_{1}}}$

$i_{\mathrm{dc}}=I_{\mathrm{dc} 0} \mathrm{e}^{-\frac{t}{\tau_{2}}}$

where $\quad \mathrm{I}_{m}=\frac{U_{m}}{\sqrt{\left(R_{\mathrm{S}}+R / 2\right)^{2}+\left[\omega\left(L_{\mathrm{S}}+L / 2\right)\right]^{2}}} ; \quad \varphi=\arctan \frac{\omega\left(L_{\mathrm{S}}+\frac{L}{2}\right)}{R_{\mathrm{S}}+\frac{R}{2}} ;$ $\tau 1=\frac{L_{S}+\frac{L}{2}}{R_{S}+\frac{R}{2}} ; \tau_{2}=\frac{\frac{2 L}{3}+L_{l}}{\frac{2 R}{3}+R_{l}}$ 

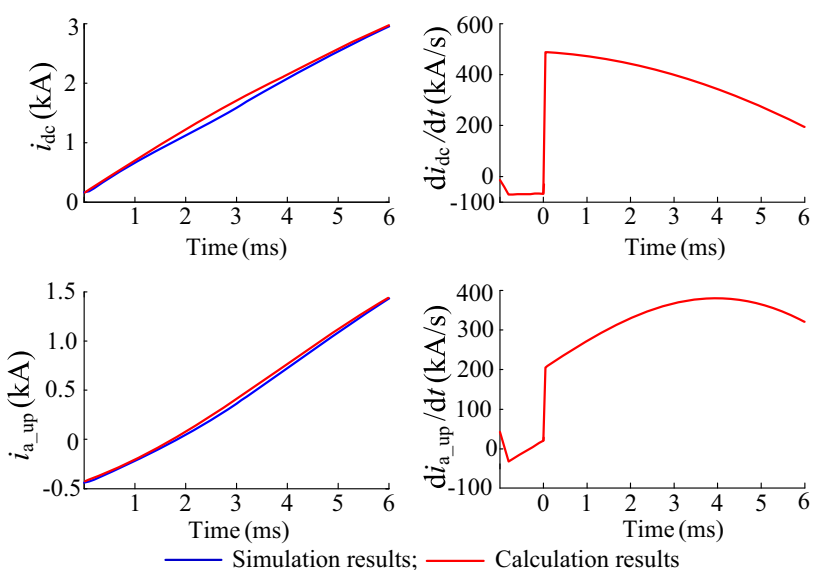

Fig. 4 Fault current and $\mathrm{d} i / \mathrm{d} t$ of DC fault during SMs normal operation stage

The upper and lower arms of each phase in the MMC are strictly symmetrical, so the currents fed into the two arms by the ac-side source are equal in value. Likewise, $i_{\mathrm{dc}}$ is evenly divided into the three phase-units. Therefore, the currents of the upper and lower arms of phase $\mathrm{A}\left(i_{\text {a_up }}\right.$ and $\left.i_{\text {a_low }}\right)$ could be expressed as

$\left\{\begin{array}{c}i_{\mathrm{a} \_ \text {up }}=\frac{i_{\mathrm{dc}}}{3}+\frac{i_{\mathrm{sa}}}{2} \\ i_{\mathrm{a} \_ \text {low }}=\frac{i_{\mathrm{dc}}}{3}-\frac{i_{\mathrm{sa}}}{2}\end{array}\right.$

Figure 7 shows the simulation and theoretical calculation results in this stage $\left(t_{1} \sim t_{2}\right)$. And the former verifies the correctness of the theoretical analysis. It can also be seen that the current of DC cable decays gradually; the current at the $\mathrm{AC}$ side has a same waveform as a threephase fault current; and the current of the arm in MMC is the superposition of the former two.

Although all of SMs are blocked in this stage, instead of being reduced, the fault currents at the $\mathrm{AC}$ side and in the converter rise significantly, which would cause greater

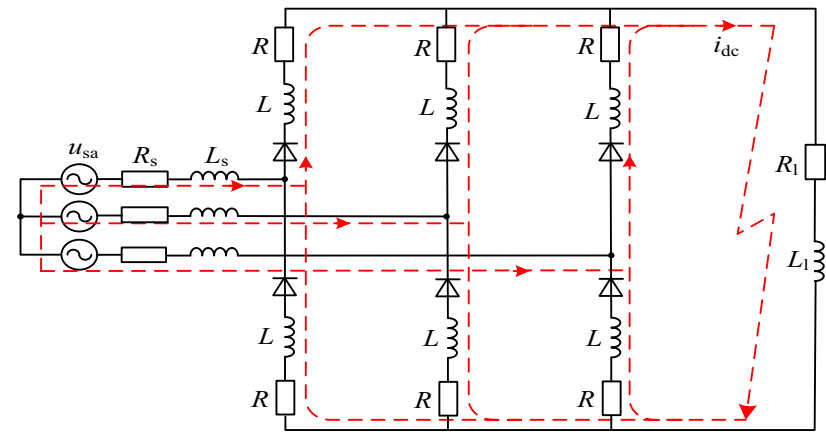

Fig. 5 Equivalent fault circuit during initial stage after blocking SMs

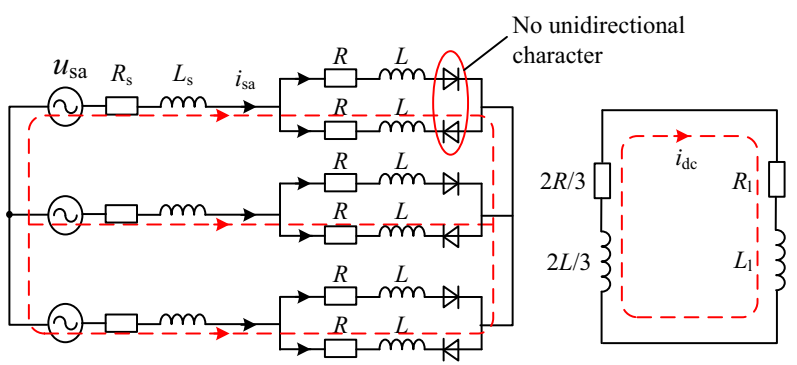

(a) Supplied from AC-side source

(b) Supplied by arm reactors

Fig. 6 Fault current decomposition during initial stage after blocking SMs

damage to the system, especially to the AC-side system and the diodes in the converter.

As shown in Fig. 7, the current of the upper arm of phase $\mathrm{C}$ arrives at zero at the time $t_{2}$, from when the diodes $\mathrm{D}_{2}$ in the corresponding arm begin to show the unidirectional characteristic. The three-phase fault state stops and the fault transient process would come into the next stage.

\subsection{Uncontrolled rectifier stage}

In this stage, the equivalent circuit is still shown as Fig. 5. However, with gradually decaying of the DC fault current $i_{\mathrm{dc}}$, there will be a time when each of the six arms has gone through a moment when its current reaches zero. And then we have to take consideration the unidirectional characteristic of the diodes $\mathrm{D}_{2}$ in all the six arms, which makes the MMC perform as an uncontrolled rectifier. So the last transient period can be considered as an uncontrolled rectifier stage approximatively.

Figure 8 shows the simulation results of the Stage 3 . After one of the arm currents ( $i_{\text {c_up }}$ in this case) arrives at zero, the remanent arms still have currents flowing through them, making the reactors in them keep on discharging and the freewheeling currents continue to decay. Gradually, the transient process gets into a stable state like an uncontrolled rectifier.

Due to the existence of the large reactor in each arm, there must be a commutation overlapping phenomenon in the MMC because of the freewheeling currents. Corresponding analysis method is similar to the way that we calculate the current in an uncontrolled rectifier which considers the effect of the inductance [18].

In summary, the fault currents at the DC side, ac side and in the converter would exist all the time. Because the equivalent impedance of the fault circuit is quite small, the currents would be considerably large. 


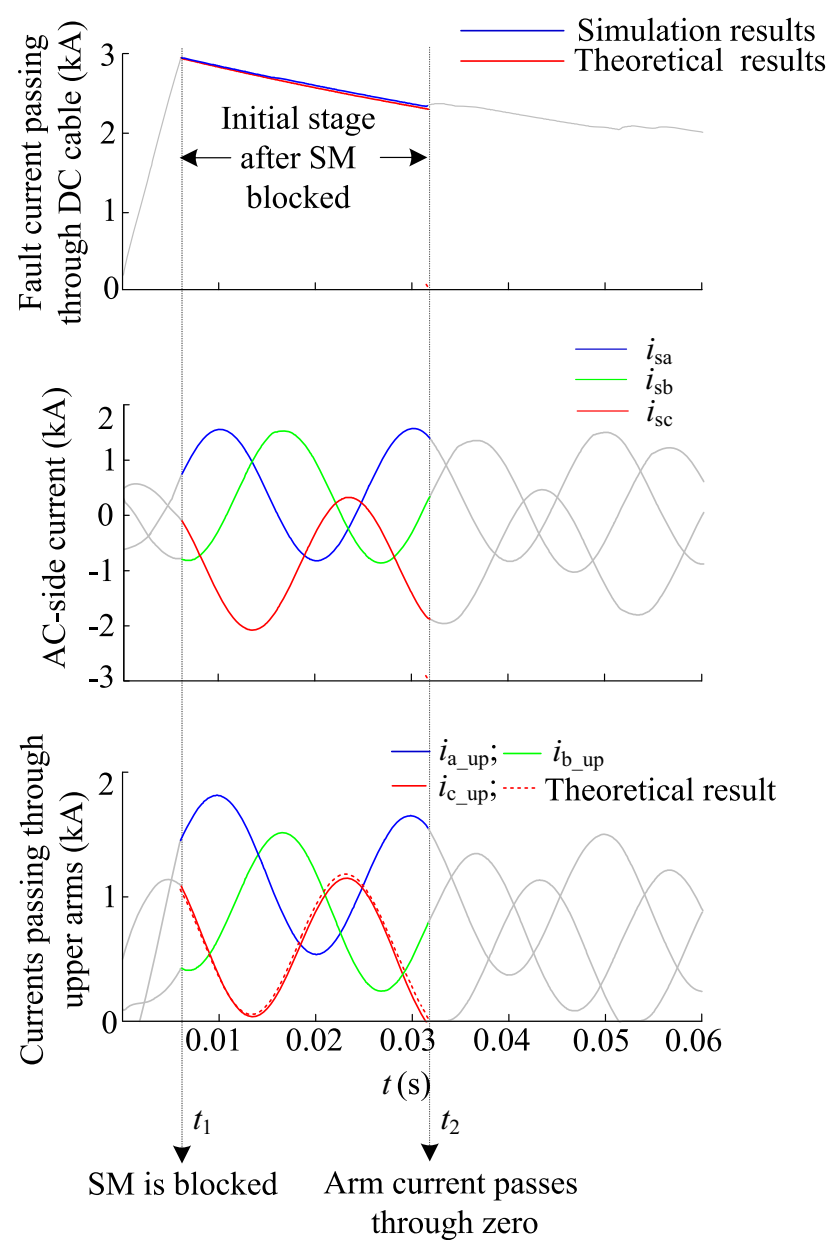

Fig. 7 Results of initial stage after SMs being blocked

\section{Protection requirements for DC system}

Figure 8 also shows the whole transient process of the DC pole-to-pole fault. According to the theoretical analysis and the simulation results, the transient process could be subdivided into three stages.

Stage 1: in this stage, SMs have not been blocked. The capacitors in the SMs and the ac-side sources feed the fault current synchronously. The arm current and the DC cable current rise rapidly. According to the transient characteristics of the DC fault, shortening this stage could reduce the overcurrent level significantly and do benefit to the recovery of the system.

Stage 2: in this stage, the reactors in the arms discharge continuously, and the AC-side sources feed three-phase fault current. For the whole DC system, especially the acside system and the devices in the MMC arms, the overcurrent in this stage is the most serious because of the three-phase fault current from the AC-side sources. So we must take measures to minimize the negative effects exerted on the system.

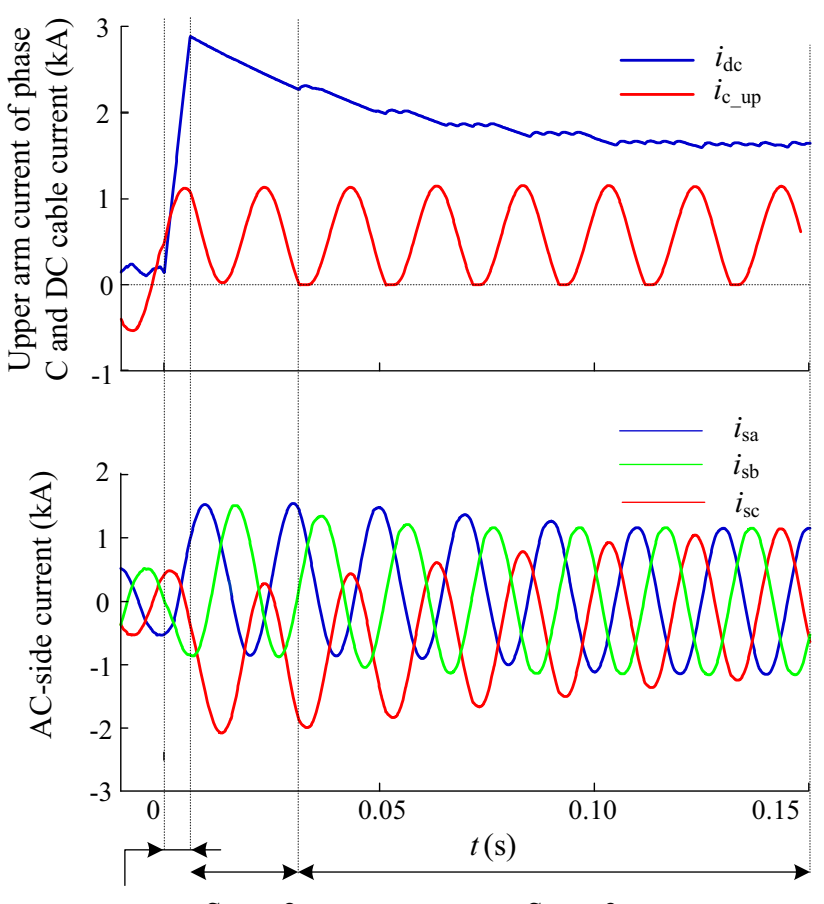

Stage 1 Stage 2

Stage 3

Fig. 8 Whole process of DC pole-to-pole fault

One method is to shorten the duration of this stage, which depends on the zero crossing time of the arm current: the earlier the arm current arrives at zero, the more quickly this stage will end. From (5) (7), we can get the conclusion that the decay speed of the continuing current of the reactors have a bearing on the zero crossing time: the smaller the decay constants $\tau_{1}$ and $\tau_{2}$ are, then the earlier the arm current arrives at zero and the less time this stage lasts for. So we can shorten the duration of this stage by decreasing the value of $\tau_{1}$ and $\tau_{2}$ which could be realized by increasing the resistance in the fault circuit artificially.

Stage 3: in this stage, the operation state of the MMC is similar to that of an uncontrolled rectifier. Because the impedance of the DC short cable is minor, the fault current of the whole system is still comparatively large. However, the DC fault cannot be interrupted with high speed and security because there is no reliable commercial DC circuit breaker up to now.

As such, the protection strategy for the MMC based DC system must have following properties.

1) Observing the transient process of the $\mathrm{DC}$ fault, the overcurrent peak is dependent on the blocking moment of the IGBTs. In another word, if the fault detection is fast enough to provide a blocking signal for the SMs (before the IGBT self-protection), the overcurrent level of the system could be reduced significantly.

2) Even if all the IGBTs are turned off during a DC fault, the fault current exists all the time because the 
freewheeling diodes act as an uncontrolled rectifier. Therefore, under the circumstance that large capacity DC circuit breaker is still far away from the commercial application, the fast and efficient fault isolating method must be proposed, which is also based on the fast fault detection.

3) In a multi-terminal DC system, a similar transient process occurs at each converter station. Therefore, identifying the fault location using single-end information becomes a key technique.

\section{Conclusions}

This paper analyzes the transient characteristics of the DC fault. Theoretical analysis and simulation test show that the transient process can be divided into three stages. In Stage 1, the main damage is caused by the high $\mathrm{d} i / \mathrm{d} t$ level to the power-electronic devices and the overcurrent to the DC cable. In Stage 2 and 3, the severe overcurrent occurs at the AC side, DC side and in the converter itself. Consequently, it is essential to design an efficient DC protection strategy, especially the high speed fault detection, fast fault isolation and reliable fault identification.

Acknowledgements This research work was supported by the National High Technology Research and Development Program of China (863 Program) (No. 2015AA050101) and the National Science Fund for Excellent Young Scholars (No. 51422703).

Open Access This article is distributed under the terms of the Creative Commons Attribution 4.0 International License (http:// creativecommons.org/licenses/by/4.0/), which permits unrestricted use, distribution, and reproduction in any medium, provided you give appropriate credit to the original author(s) and the source, provide a link to the Creative Commons license, and indicate if changes were made.

\section{Appendix A}

The MMC-based DC system is built on the MATLAB/ Simulink. MMC has the same configuration with that shown in Fig. 1. The concrete parameters of the system are listed in Table A1.

Table A1 Parameters of MMC-based DC system

\begin{tabular}{ll}
\hline Parameters & Value \\
\hline Rated power & $10 \mathrm{MVA}$ \\
Rated DC voltage & $\pm 12 \mathrm{kV}$ \\
Rated AC voltage & $13.8 \mathrm{kV}$ \\
Arm reactor & $60 \mathrm{mH}$ \\
Sub-module capacitor & $1000 \mu \mathrm{F}$ \\
Resistance of DC cable & $0.0189 \Omega / \mathrm{km}$ \\
Inductance of DC cable & $0.159 \mathrm{mH} / \mathrm{km}$ \\
\hline
\end{tabular}

\section{References}

[1] Cheng L, Liu MJ, Sun YZ et al (2013) A multi-state model for wind farms considering operational outage probability. Mod Power Syst Clean Energy 1(2):177-185. doi:10.1007/s40565013-0025-Z

[2] Meng J, Mu YF, Wu JZ et al (2015) Dynamic frequency response from electric vehicles in the Great Britain power system. Mod Power Syst Clean Energy 3(2):203-211. doi:10.1007/ s40565-015-0124-0

[3] Baran ME, Mahajan NR (2003) DC distribution for industrial systems: Opportunities and challenges. IEEE Trans Ind Appl 39(6):1596-1601

[4] Flourentzou N, Agelidis VG, Demetriades GD (2009) VSCbased HVDC power transmission systems: An overview. IEEE Trans Power Electron 24(3):592-602

[5] Al Jowder FAR, Ooi BT (2004) VSC-HVDC station with SSSC characteristics. IEEE Trans Power Electron 19(4):1053-1059

[6] Jiang HB, Ekstrom A (1998) Multiterminal HVDC systems in urban areas of large cities. IEEE Trans Power Deliver 13(4):1278-1284

[7] Xue YL, Xu Z, Tu QR (2012) Modulation and control for a new hybrid cascaded multilevel converter with DC blocking capability. IEEE Trans Power Deliver 27(4):2227-2237

[8] Gnanarathna UN, Gole AM, Jayasinghe RP (2011) Efficient modeling of modular multilevel HVDC converters (MMC) on electromagnetic transient simulation programs. IEEE Trans Power Deliver 26(1):316-324

[9] Hagiwara M, Akagi H (2009) Control and experiment of pulsewidth-modulated modular multilevel converters. IEEE Trans Power Electron 24(7):1737-1746

[10] Marquardt R (2011) Modular multilevel converter topologies with DC-short circuit current limitation. In: Proceedings of the IEEE 8th international conference on power electronics and ECCE Asia (ICPE \& ECCE'11), Jeju, Republic of Korea, 30 May-3 Jun 2011, pp 1425-1431

[11] Franck CM (2011) HVDC circuit breakers: A review identifying future research needs. IEEE Trans Power Deliver 26(2):998-1007

[12] Tang LX, Ooi BT (2007) Locating and isolating DC faults in multi-terminal DC system. IEEE Trans Power Deliver 22(3):1877-1884

[13] Schmitt D, Wang Y, Weyh T, et al (2012) DC-side fault current management in extended multiterminal-HVDC-grids. In: Proceedings of the 9th international multi-conference on systems, signals and devices (SSD'12), Chemnitz, Germany, 20-23 Mar 2012, 5 pp

[14] Li XQ, Song Q, Liu WH et al (2013) Protection of nonpermanent faults on DC overhead lines in MMC-based HVDC systems. IEEE Trans Power Deliver 28(1):483-490

[15] Xue YL, Xu Z, Tang G (2014) Self-start control with grouping sequentially precharge for the C-MMC-based HVDC system. IEEE Trans Power Deliver 29(1):187-198

[16] Yang J, Fletcher JE, O'Reilly J (2012) Short-circuit and ground fault analyses and location in VSC-Based DC network cables. IEEE Trans Ind Electron 59(10):3827-3837

[17] Wang SS, Zhou XX, Tang GF et al (2011) Analysis of submodule overcurrent caused by DC pole-to-pole fault in modular multilevel converter HVDC system. P CSEE 31(1):1-7 (in Chinese)

[18] Sakui M, Fujita H (1994) An analytical for calculating harmonic currents of a three-phase diode-bridge rectifier with DC filter. IEEE Trans Power Electron 9(6):631-637

Bin LI obtained the B.Sc., M.Sc. and Ph.D. degrees from Tianjin University in 1999, 2002 and 2005 respectively. He was an academic 
visitor of the University of Manchester, U.K. in 2006. And he worked in the design and application of protection relays in AREVA Company U.K. from 2008 to 2009. Currently, he is a professor of the School of Electrical Engineering and its Automation, Tianjin University, Tianjin, China. His main research field is involved in the protection and control of power system.

Jiawei HE obtained the B.Sc. degree from Tianjin University in 2014. Now he is a postgraduate of Tianjin University. His research field is involved in protection and control of DC power system.

Jie TIAN Ph.D., professorate senior engineer,general engineer of NR Electric Co. Ltd. He works on ultra-high-voltage DC transmission, flexible DC transmission and flexible AC transmission technology.
Yadong FENG Ph.D., senior engineer, general engineer of NR Electric Co. Ltd. He works on control and protetion technology of AC and DC system, intelligent devices of converting station and flexible DC transmission.

Yunlong DONG master, senior engineer, engineer of NR Electric Co. Ltd. He works on ultra-high-voltage DC transmission, flexible DC transmission and flexible $\mathrm{AC}$ transmission technology. 